\title{
Prophylactic Radiation Therapy is Safe and Effective Treatment for the Prevention of Recurrent Heterotopic Ossification in Elbow and Knee Joints
}

\author{
M. V. Mishra \\ Thomas Jefferson University and Hospitals \\ L. Austin \\ Thomas Jefferson University and Hospitals \\ J. Parvisi \\ Thomas Jefferson University and Hospitals \\ M. Ramsey \\ Thomas Jefferson University and Hospitals
}

FoNpushthisamedepdditional works at: https://jdc.jefferson.edu/bodinejournal

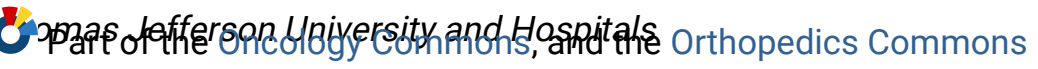

Let us know how access to this document benefits you

\section{Recommended Citation}

Mishra, M. V.; Austin, L.; Parvisi, J.; Ramsey, M.; and Showalter, T. N. (2010) "Prophylactic Radiation

Therapy is Safe and Effective Treatment for the Prevention of Recurrent Heterotopic Ossification in Elbow and Knee Joints," Bodine Journal: Vol. 3 : Iss. 1 , Article 37.

DOI: https://doi.org/10.29046/TBJ.003.1.036

Available at: https://jdc.jefferson.edu/bodinejournal/vol3/iss1/37

This Article is brought to you for free and open access by the Jefferson Digital Commons. The Jefferson Digital Commons is a service of Thomas Jefferson University's Center for Teaching and Learning (CTL). The Commons is a showcase for Jefferson books and journals, peer-reviewed scholarly publications, unique historical collections from the University archives, and teaching tools. The Jefferson Digital Commons allows researchers and interested readers anywhere in the world to learn about and keep up to date with Jefferson scholarship. This article has been accepted for inclusion in Bodine Journal by an authorized administrator of the Jefferson Digital Commons. For more information, please contact: JeffersonDigitalCommons@jefferson.edu. 


\title{
Prophylactic Radiation Therapy is Safe and Effective Treatment for the Prevention of Recurrent Heterotopic Ossification in Elbow and Knee Joints
}

\author{
Mishra, M.V., ${ }^{1}$ Austin, L., ${ }^{2}$ Parvisi, J., ${ }^{2}$ Ramsey, M., ${ }^{2}$ Showalter, T.N. ${ }^{1}$ \\ ${ }^{1}$ Department of Radiation Oncology, Thomas Jefferson University and Hospitals, Philadelphia, PA \\ ${ }^{2}$ Rothman Institute, Thomas Jefferson University and Hospitals, Philadelphia, PA
}

\section{Background}

Prophylactic radiation therapy (RT) is an established adjuvant therapy for heterotopic ossification (HO) of the hip when delivered in the immediate pre- or post-operative setting. Its role in prevention of recurrence after excision of $\mathrm{HO}$ is supported by randomized trials for $\mathrm{HO}$ of the hip, but there is scant evidence to support a similar approach in non-hip joints. In the current study, we evaluate radiologic and functional outcomes after prophylactic radiation therapy (RT) for prevention of $\mathrm{HO}$ of the knee and upper extremity [elbow and metacarpophalangeal (MCP) joints].

\section{Methods}

With IRB approval, patients treated at our institution with prophylactic RT for non-hip HO from 1998-2009 were identified. Records were reviewed, including pre- and post-operative records, operative reports, and radiography. The primary objectives were to determine the safety and rate of treatment failure, as defined by need, for further surgical intervention.

\section{Results}

A total of 30 patients received prophylactic RT for $\mathrm{HO}$ of the elbow $(\mathrm{n}=21), \operatorname{MCP}$ joint $(\mathrm{n}=1)$, and knee $(\mathrm{n}=8)$. Twenty-nine of the 30 patients were treated within 24-48 hours post-operatively and 1 patient was treated within 24 hours pre-operatively. Based on institutional policy, only patients considered to be at high risk of recurrence were selected to receive prophylactic RT. The median patient age was 47 years (range, 15-78 years). Patients were treated to a dose of $7 \mathrm{~Gy}$ in one fraction, with 2 parallel opposed fields (anteriorposterior and posterior-anterior). Median field size was was $9.0 \mathrm{~cm}$ wide (range, $7.2-18.1 \mathrm{~cm}$ ) by $12.0 \mathrm{~cm}$ long (range, $9.6-19.7 \mathrm{~cm}$ ) for the elbow and $13.75 \mathrm{~cm}$ wide (range, $8-34.7 \mathrm{~cm}$ ) by $12.35 \mathrm{~cm}$ long (range, $8.5-16.4 \mathrm{~cm}$ ) for the knee. Complications following treatment included: 2 patients with post-operative wound infections, 1 patient with a ruptured triceps tendon, and 1 patient with a fracture within the treatment field. Follow-up information was available for $26 / 30$ patients, with a median follow-up time of 16 months (range 2-143 months). Recurrent $\mathrm{HO}$, requiring surgical re-excision, developed in $10.5 \%(n=2)$ of patients who were followed for upper extremity $\mathrm{HO}$ $(n=19)$. For patients followed after RT for HO of the knee $(n=7)$, there were no recurrences of $\mathrm{HO}$ that required further intervention.

\section{Conclusion}

This represents the largest reported series to evaluate the safety and efficacy of prophylactic RT for prevention of HO for non-hip joints. In this group of patients at high risk for developing further $\mathrm{HO}$, prophylactic RT appears to be a safe adjunct to surgery and is effective in prevention of $\mathrm{HO}$ recurrence. Results are similar to published reports of $\mathrm{HO}$ of the hip and support the use of surgical excision and perioperative, prophylactic $\mathrm{RT}$ for $\mathrm{HO}$ of non-hip joints. 